\title{
Thoracoscopic Tracheoesophageal N-fistula Repair using a 5.8-mm Miniature Stapler for Fistula Division
}

\author{
Anne-Sophie Holler ${ }^{1}$ Martin Schwind ${ }^{1} \quad$ Krystyna Poplawska $^{2} \quad$ Oliver J. Muensterer $^{1}$
}

${ }^{1}$ Department of Pediatric Surgery, University Medicine of the Johannes Gutenberg University Mainz, Mainz, Germany

2 Department of Pediatric Pulmonology, University Medicine of the Johannes Gutenberg University Mainz, Mainz, Germany
Address for correspondence Anne-Sophie Holler, MD, Department of Pediatric Surgery, University Medicine of the Johannes Gutenberg University Mainz, Langenbeckstr. 1, Mainz 55131, Germany (e-mail: anne-sophie.holler@unimedizin-mainz.de).

Eur J Pediatr Surg Rep 2017;5:e55-e56.

\section{New Insights and the Importance for the Pediatric Surgeon}

We report a case of thoracoscopic N-type tracheoesophageal fistula repair using a 5.8-mm miniature stapler for fistula division. Our patient developed recurrent tracheoesophageal fistula 3 months postoperatively. One of the reasons for late recurrence may have been the small size of the fistula and not interposing a pleural or muscle flap primarily.

\section{Introduction}

$\mathrm{N}$-type tracheoesophageal fistula without atresia is a rare congenital tracheoesophageal anomaly. Open surgical repair through a right cervical incision is the standard procedure in most hospitals. ${ }^{1-3}$ Thoracoscopic repair has been described but is performed less frequently. ${ }^{4}$

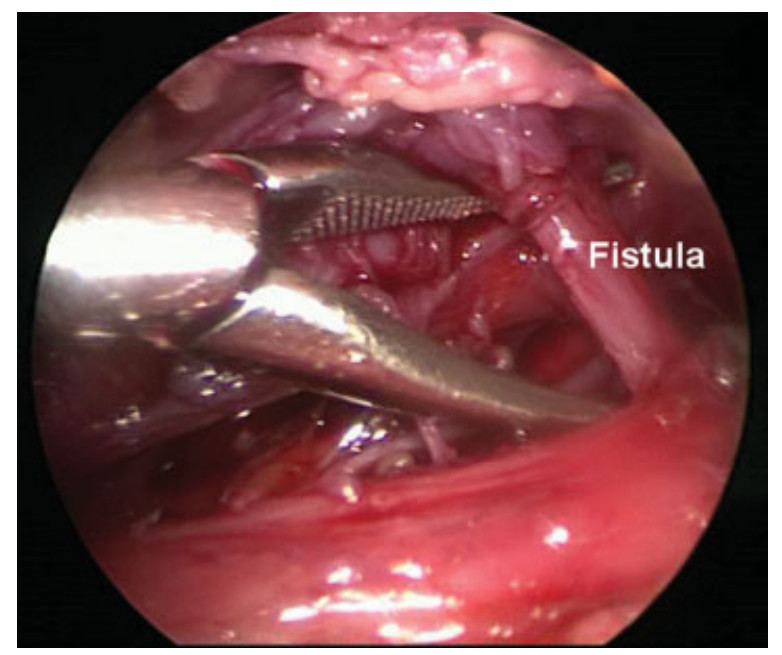

Fig. 1 Intraoperative image of the first surgery demonstrating the very small fistula size.
We report a case of a 7-week-old girl born at 36 gestational weeks who presented with episodes of coughing and cyanosis during feeds. Bronchoscopy showed an N-type tracheoesophageal fistula. Thoracoscopic $\mathrm{N}$-fistula repair was performed

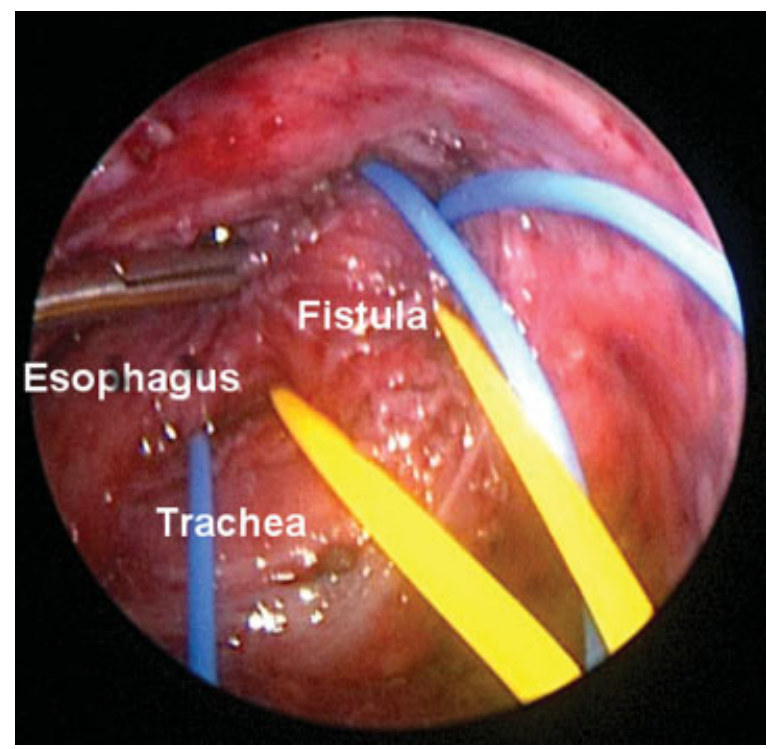

Fig. 2 Intraoperative image of the thoracoscopic reclosure of the fistula. The recurrent fistula is retracted with the yellow loop, the esophagus with the blue loops.

(C) 2017 Georg Thieme Verlag KG Stuttgart - New York

\section{License terms}

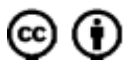

June 21, 2017

accepted

July 16, 2017
DOI https://doi.org/

10.1055/s-0037-1606192.

ISSN 2194-7619. 
using a 5.8-mm stapler for fistula division (- Fig. 1, - Video 1). There were no intraoperative or postoperative complications. Three months later, the girl presented with influenza $A$ pneumonia. Cough episodes with feedings recurred. A contrast study showed recurrent fistula, and reclosure of the fistula was performed thoracoscopically (-Fig. 2).

\section{Video 1}

Initially, bronchoscopy was performed and a guide wire was passed through the fistula for easier identification. Video 1 shows the endoscopic view of the esophagus with the guide wire in place. Subsequently, thoracoscopy was performed using 3-mm trocars and instruments. The esophagus, trachea, and fistula were then dissected. Once the fistula was completely visualized, the anterior port was upsized to a 5-mm trocar, the miniature stapler was introduced, and fistula division was performed using the miniature stapler. Online content including video sequences viewable at: www.thieme-connect.com/products/ejournals/html/ 10.1055/s-0037-1606192.
To our knowledge, this is the first report of thoracoscopic repair of a tracheoesophageal $\mathrm{N}$-type fistula using a $5.8-\mathrm{mm}$ stapler for fistula division. In our case, the initial success was overshadowed by late recurrence. We hypothesize that the very small fistula size may have contributed to recurrence as even the single staples were too big to approximate the fine tissue adequately. Therefore, we would currently advise against using the miniature stapler for this indication. The interposition of a pleural flap may have prevented recurrence.

\section{References}

1 Al-Salem AH, Mohaidly MA, Al-Buainain HM, Al-Jadaan S, Raboei E. Congenital H-type tracheoesophageal fistula: a national multicenter study. Pediatr Surg Int 2016;32(05):487-491

2 Zani A, Jamal L, Cobellis G, et al. Long-term outcomes following H-type tracheoesophageal fistula repair in infants. Pediatr Surg Int 2017;33(02):187-190

3 Fallon SC, Langer JC, St Peter SD, et al. Congenital H-type tracheoesophageal fistula: A multicenter review of outcomes in a rare disease. J Pediatr Surg 2017. Doi: 10.1016/j.jpedsurg.2017.05.002 [epub ahead of print]

4 Aziz GA, Schier F. Thoracoscopic ligation of a tracheoesophageal H-type fistula in a newborn. J Pediatr Surg 2005;40(06):e35-e36 